\title{
BMJ Open Manual therapy for unsettled, distressed and excessively crying infants: a systematic review and meta-analyses
}

\author{
Dawn Carnes, ${ }^{1,2,3}$ Austin Plunkett, ${ }^{1,3}$ Julie Ellwood, ${ }^{3}$ Clare Miles ${ }^{1}$
}

To cite: Carnes D, Plunkett A, Ellwood J, et al. Manual therapy for unsettled, distressed and excessively crying infants: a systematic review and meta-analyses. BMJ Open 2018;8:e019040. doi:10.1136/ bmjopen-2017-019040

- Prepublication history and additional material for this paper are available online. To view these files, please visit the journal online (http://dx.doi. org/10.1136/bmjopen-2017019040).

Received 9 August 2017 Revised 13 November 2017 Accepted 28 November 2017

Check for updates

${ }^{1}$ Barts and The London School of Medicine and Dentistry, Centre for Primary Care and Public Health, Queen Mary University of London, London, UK

${ }^{2}$ Faculty of Health, Universtiy of Applied Sciences, Western Switzerland, Fribourg,

Switzerland

${ }^{3}$ National Council for Osteopathic Research, London, UK

Correspondence to

Dr Dawn Carnes;

d.carnes@qmul.ac.uk

\section{ABSTRACT}

Objective To conduct a systematic review and metaanalyses to assess the effect of manual therapy interventions for healthy but unsettled, distressed and excessively crying infants and to provide information to help clinicians and parents inform decisions about care. Methods We reviewed published peer-reviewed primary research articles in the last 26 years from nine databases (Medline Ovid, Embase, Web of Science, Physiotherapy Evidence Database, Osteopathic Medicine Digital Repository , Cochrane (all databases), Index of Chiropractic Literature, Open Access Theses and Dissertations and Cumulative Index to Nursing and Allied Health Literature). Our inclusion criteria were: manual therapy (by regulated or registered professionals) of unsettled, distressed and excessively crying infants who were otherwise healthy and treated in a primary care setting. Outcomes of interest were: crying, feeding, sleep, parent-child relations, parent experience/satisfaction and parent-reported global change. Results Nineteen studies were selected for full review: seven randomised controlled trials, seven case series, three cohort studies, one service evaluation study and one qualitative study. We found moderate strength evidence for the effectiveness of manual therapy on: reduction in crying time (favourable: -1.27 hours per day $(95 \% \mathrm{Cl}$ -2.19 to -0.36$)$ ), sleep (inconclusive), parent-child relations (inconclusive) and global improvement (no effect). The risk of reported adverse events was low: seven non-serious events per 1000 infants exposed to manual therapy ( $n=1308)$ and 110 per 1000 in those not exposed. Conclusions Some small benefits were found, but whether these are meaningful to parents remains unclear as does the mechanisms of action. Manual therapy appears relatively safe.

PROSPERO registration number CRD42016037353.

\section{INTRODUCTION}

Unsettled infant behaviour and colic are terms used to describe a range of behaviours in infants aged up to 12 months that include prolonged episodes of crying, difficulties with sleeping and/or feeding. ${ }^{1}$ Reports suggest a prevalence of approximately $20 \%,{ }^{2}$ and the incidence is equal between sexes. ${ }^{3}$ The problems are found more commonly in first-borns and infants who have siblings who also had this condition. ${ }^{4-6}$ High levels of multiple

\section{Strengths and limitations of this study}

Meaningful outcomes for parents with distressed, unsettled and excessively crying infants were investigated to help inform their decisions about seeking manual therapy care for their infants.

- Compiling evidence for distressed, unsettled and excessively crying infants based on multiple 'clinical diagnoses' using varied definitions is difficult.

- The mechanism of action of complex interventions was not explained by the pragmatic research investigations used in this review.

- Low to moderate quality studies limited the certainty of conclusions, suggesting they are liable to change with further research.

health service use have been found in the postpartum period, including visits to emergency departments. ${ }^{14}$ A cost burden analysis found that the annual cost to the UK National Health Service of infant crying and sleeping problems in the first 12 weeks of life was $£ 65$ million. ${ }^{5}$ There are associations between unsettled infant behaviour and high maternal depression scores, ${ }^{6}$ and the natural crying peak at 6 weeks coincides with the peak age for severe infant injury or death as a result of child abuse. $^{7}$

Manyaetiological factors for unsettled infant behaviour have been explored including diet, feeding and digestive issues, ${ }^{8-11}$ musculoskeletal strains and disorders, ${ }^{12}{ }^{13}$ developmental progress $^{14-17}$ and parenting. ${ }^{18-22}$ Despite extensive research, causative factors and effective treatment remain elusive.

Medicalising these symptoms is controversial as they are seen as self-limiting with infants normally settling after 12 weeks. However, coping with these infants during this period can be very difficult.

Manual therapists offer a mix of health screening, education, advice, psychological support and touch therapy for these infants. Manual treatment is based on the premise that infants may have musculoskeletal strains or limitations affecting comfort, feeding and 
gut motility causing distress. A previous Cochrane review (2012) of manual therapy and colic meta-analysed data from six randomised controlled trials (RCTs) and found small positive (statistically significant) changes in crying time outcomes overall. However, a sensitivity analysis of data from only RCT studies where parents were blinded to treatment did not show beneficial effects. ${ }^{23}$ Other analyses showed a small beneficial effect for sleep but not for 'recovery'. The studies included in this review were generally small and methodologically prone to bias, so definitive conclusions could not be drawn and effects were downgraded accordingly. ${ }^{23}$

There are some concerns around the safety of manual techniques in the treatment of infants, but published data of cases of serious adverse events are rare. ${ }^{24}$ No reviews to our knowledge have explored qualitative research and non-specific effects such as parental confidence and satisfaction. In this review, we aimed to update the Cochrane review $^{23}$ of RCTs for crying time and investigate non-RCT studies and outcomes that are important to parents, rather than biomedical markers alone that might be of more interest to primary researchers exploring aetiology as our selected population was infants that were considered healthy.

\section{METHOD}

\section{Types of studies}

We included the following types of peer-reviewed studies in our search: RCTs, prospective cohort studies, observational studies, case-control studies, case series, questionnaire surveys and qualitative studies. We excluded single-case studies and non-peer reviewed literature (editorials, letters, master's and undergraduate theses). Systematic reviews were identified to inform our research and for citation tracking. There were no language restrictions in our search criteria.

\section{Types of participants}

Participants were aged between 0 months and 12 months (infants) when they received manual therapy treatment. They were healthy, thriving and not receiving other medical interventions. Their presenting symptoms were excessive crying, distress and unsettledness; they might also be described as having colic, constipation, breastfeeding/feeding difficulties and/or gastro-oesophageal reflux/discomfort.

'Colic' was determined using the Wessel 'rule of three ${ }^{25}$ or Rome III ${ }^{26}$ criteria. The latter considers infants to have colic if they were thriving and healthy but had paroxysms of irritability, fussing or crying lasting for a total or more than 3 hours a day and occurring on more than 3 days a week for more than 1 week. ${ }^{26}$

We excluded studies that included infants requiring treatment for conditions that needed specialist or hospital-based clinical care for conditions such as: respiratory disorders, developmental disorders (learning and motor), cystic fibrosis, cerebral palsy, otitis media, neuralgia, congenital torticolis or musculoskeletal trauma. We also excluded studies about plagiocephaly or brachycephaly.

\section{The intervention}

We included studies where the manual therapy intervention was delivered in primary care by statutorily registered or regulated professional(s). This included osteopaths, chiropractors, physiotherapists and any other discipline using manual contact as the primary therapeutic component. The intervention or therapy had to involve physical and/or manual contact with the patient for therapeutic intent, administered without the use of mechanical, automated, electronic, computer or pharmacological aids/ products/procedures. We excluded mixed or multidisciplinary interventions where the response to the manual therapy elements would have been unclear/undeterminable. Studies where the professional trained a non-professional to deliver the therapy or where parents delivered the therapy were excluded also.

\section{Types of outcome measures}

Outcomes of interest were unsettled behaviours, experience/satisfaction and global change scores. Unsettled behaviours included, for example, excessive crying, lack of sleep, displays of distress or discomfort (back arching and drawing up of legs) and difficulty feeding. Adverse events data were also collected.

\section{Selection of articles}

Nine electronic databases were searched from January 1990 to January 2017 in the last 26 years: Medline Ovid, Embase, Web of Science (WOS), Physiotherapy Evidence Database, Osteopathic Medicine Digital Repository, Cochrane (all databases), Index of Chiropractic Literature, Open Access Theses and Dissertations and Cumulative Index to Nursing and Allied Health Literature. We selected this timeframe because our scoping work revealed that most papers prior to January 1990 were theory-driven position papers on the manual therapy care of infants and for pragmatic reasons in terms of access to full-text original articles.

The main search string (modified for the different engines) is included in the electronic online supplementary appendices. It included the key terms: musculoskeletal, manipulation, manual and physical therapy, physiotherapy, osteopathy and chiropratic with infant baby and new borns. We updated the search to the end of January 2017 using Medline Ovid and search alerts from Embase, Cochrane and WOS. We also located articles through peer networks. Four reviewers (the authors in two teams of two) reviewed the titles and abstracts, then the full texts independently. Where there was disagreement between the reviewers, a third reviewer from the other team arbitrated the final decision to select reject. Review articles retrieved in the search were citation tracked to identify additional studies. Covidence software was used to organise and classify the articles. ${ }^{27}$ See figure 1 for a flow chart of the search process. 


\section{1,423 references retrieved from searches and peer networks}

\section{2,588 duplicate references}

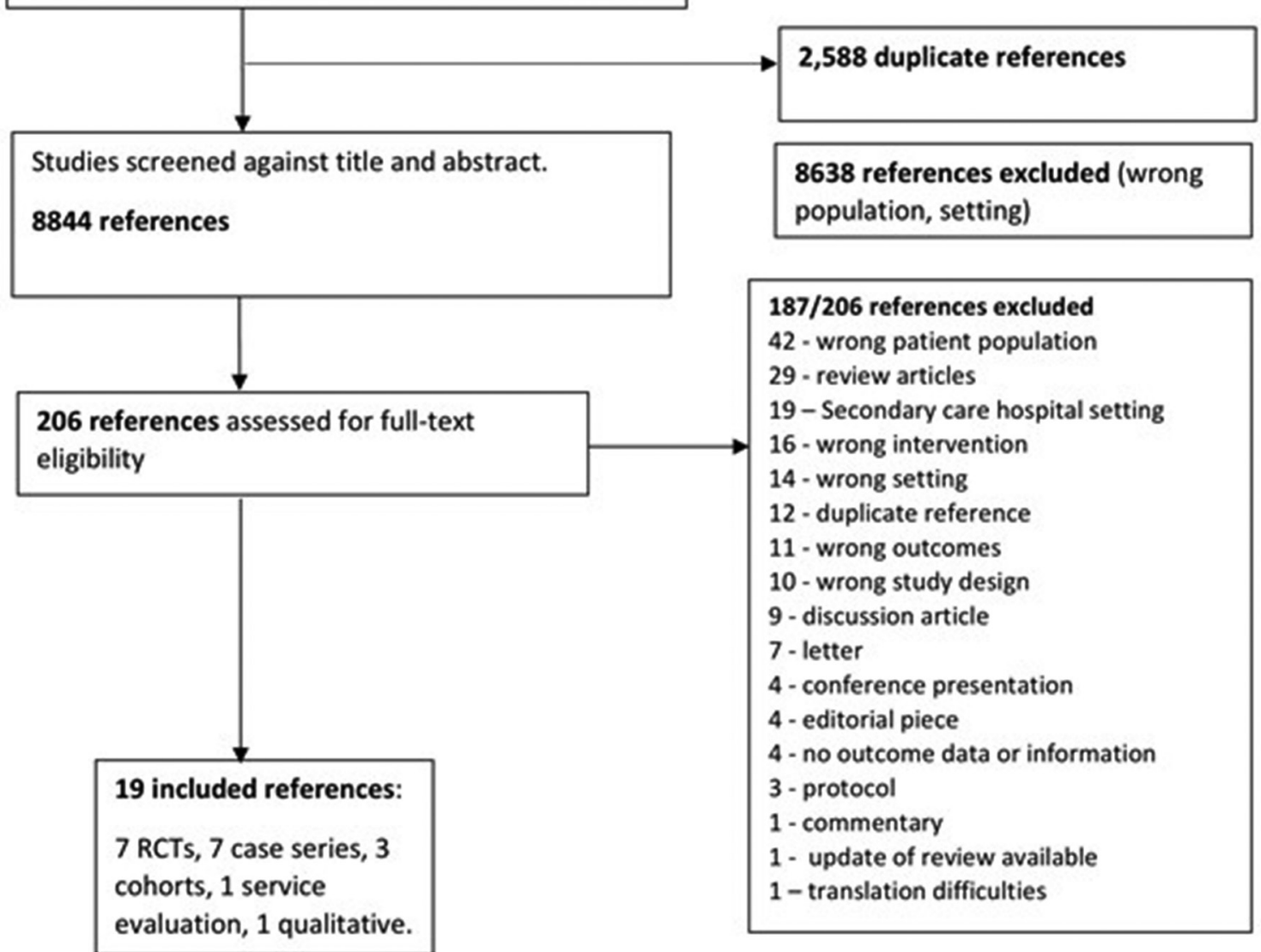

Figure 1 Flow chart of search process for the review. RCTs, randomised controlled trials.

\section{Quality appraisal of included studies}

Two reviewers independently rated the quality of each included study (either $\mathrm{CM} / \mathrm{JE}$ or DC/AP). We used the appropriate quality appraisal tools for each type of study design. ${ }^{28-30}$ An overall quality score for each study was assigned by summing the number of quality criteria that were present. For RCTs: six risk of bias criteria were assessed ${ }^{28}$ (5-6 quality criteria evaluated as present indicated low risk of bias=high quality, 3-4=moderate quality and 1-2=low quality). For cohorts: 11 quality criteria were assessed ${ }^{29}$ (8-11 quality criteria evaluated as present=high quality, $4-7=$ moderate quality, $0-3=$ low quality). For case series: nine quality criteria were assessed $^{30}$ (if 7-9 quality criteria were present=high quality, if 3-6=moderate quality and if $0-3=$ low quality). For qualitative studies: 10 criteria were assessed ${ }^{29}$ (if $8-10$ quality criteria were present=high quality, 4-7=moderate quality and $0-3=$ low quality). All low quality cohort and case series studies were regarded as severely methodologically flawed and were not included in the final analyses.

\section{Data extraction and synthesis}

One reviewer extracted the data and another checked the data extractions (all authors).

\section{Analyses}

We aimed to meta-analyse data for RCTs and matched or paired cohort studies. For RCTs, we planned to extract final value scores for each group and convert them to standardised mean differences and weighted mean differences for comparison using a random effects model due to the expected differences in treatment protocols and effects between studies. Where there was a majority of either change or final value scores, we planned sensitivity analysis to check 'consistency' / meaning of the meta-analyses. We planned to extract risk ratios (RR) for comparison of adverse events between treatment and control groups. $\mathrm{I}^{2}$ was used to calculate heterogeneity. RevMan software (V.5.3) was used to conduct the meta-analyses.

For non-RCT studies, analyses proposed were descriptive and narrative, but change scores and RRs were extracted where possible. If there were a sufficient number of qualitative studies, we proposed to organise and synthesise findings from the qualitative data, by identifying emergent themes and subthemes.

\section{Strength of evidence}

We rated the strength of evidence across studies for each outcome, as either high, moderate or low, taking note of 
the quality and overall direction of results (inconclusive, favourable or unfavourable) ${ }^{31}$ Strength of evidence was considered as follows:

\section{High}

Consistent results from at least two high-quality RCTs, or other well-designed studies, conducted in representative populations where the conclusion is unlikely to be strongly affected by future studies.

\section{Moderate}

Available evidence from at least one higher quality RCT or two or more lower quality RCTs but constrained by: number, size, quality, inconsistency in findings and limited generalisability to clinical practice. The conclusions are likely to be affected by future studies.

\section{Low}

Evidence was insufficient with limitations in data provision, number, power, quality, inconsistency in results and findings not generalisable to clinical practice. All studies that were rated as low quality were treated as inconclusive regardless of author findings.

Two reviewers rated the quality and strength of evidence, and a consensus vote was used in cases of disagreement.

\section{RESULTS}

\section{Search results}

A total of 11423 studies were retrieved. After duplicate removal, 8844 studies remained. There were 8638 references excluded by title and abstract predominantly because the population was not appropriate; for example, the children were too old and/or treatment settings were not primary care. We acquired full text for 206 references and 19 of these fulfilled our inclusion criteria. Reasons for exclusion are listed in figure 1.

There were 19 primary studies included: seven RCTs, ${ }^{32-38}$ seven case series, ${ }^{39-45}$ three cohort studies, ${ }^{46-48}$ one service evaluation survey ${ }^{49}$ and one qualitative study. ${ }^{50}$ One other primary study was excluded due to translation difficulties of technical terms in Chinese medicine. ${ }^{51}$ All studies were published between January 1990 and January 2017. Countries represented across the studies were the UK, ${ }^{32-34} 41-43464749$ USA, ${ }^{35} 4048$ Canada, ${ }^{38}$ Australia, ${ }^{39} 4450$ Norway $^{36}$ and Denmark. ${ }^{37} 45$ The following conditions were represented in the studies: colic (11 studies), ${ }^{32-34} 363739404345-47$ gastro-oesophageal reflux (2 studies) ${ }^{35}{ }^{40}$; breastfeeding difficulties ( 5 studies) 3842444849 and infant signs of distress (described as headache) (1 study). ${ }^{41}$ With the exception of four studies, all used chiropractic intervention. The other four studies used massage therapy ${ }^{35}$ and osteopathic intervention. ${ }^{33} 3849$ Eight studies used control groups. ${ }^{32-36} 384647$ The controls varied across studies, from no physical treatment $^{33} 34364647$ to a sham treatment ${ }^{35} 38$ or drug. ${ }^{37}$ See table 1 for characteristics of included studies.
In the few cases where there was uncertainty with selection choice, these were all resolved after discussion with a third reviewer.

\section{Quality assessment}

The methodological quality of the studies varied (table 2). Five studies were rated as high quality: four RCTs (low risk of bias) $)^{32} 343538$ and a qualitative study. ${ }^{50}$ Seven were of moderate quality. ${ }^{33} 363942434549$ The remaining seven were rated as low quality due to severe methodological flaws (eg, small samples, the treating clinician observed and reported outcomes) $3739414446-48$ (table 2). The non-RCT studies rated as low quality were excluded from further analyses.

\section{Review findings}

Table 3 shows the results from studies reporting similar outcomes. Six studies reported outcomes related to improvement in feeding, ${ }^{38} 4244$ 48-50 seven reported a reduction in crying time, ${ }^{32-34} 36374546$ five reported global improvement in symptoms, ${ }^{32} 34363940$ four reported sleep outcomes $^{32} 333846$ and three reported outcomes about parent-child relations. ${ }^{33} 3546$ The remaining outcomes were from one study only.

\section{Meta-analyses}

A meta-analysis was only possible for the RCTs with outcomes measuring reduction in crying time and for adverse events.

Meta-analyses for global improvement in symptoms, parent-child relations, sleeping time and feeding were not possible because: several studies did not have a 'no-treatment' control group, ${ }^{32} 3940424448-50$ did not present data at their primary endpoints, ${ }^{34}{ }^{36}$ did not collect enough data or the data and outcomes were too heterogeneous.

\section{Reduction in crying time}

Seven studies reported data on crying time. ${ }^{32-34} 36374546$ There were sufficient data from four studies in the form of final value scores for the outcome of reduced crying time that could be meta-analysed for comparison of treatment effects. This replicated a previous meta-analysis. ${ }^{23}$ Our replicated meta-analysis (figure 2) gave a slightly different but still significant outcome for reduced crying time of -1.27 (95\% CI -2.19 to -0.36 ) hours per day (figure 2 ). The difference is due to apportioned weighting given by the different versions of RevMan. One study ${ }^{37}$ used dimethicone as a comparison; the other studies' controls were no treatment or placebo. We classified dimethicone as a placebo control (see figure 2). Parents were blinded to their child's treatment in only two of the studies included in the meta-analysis. ${ }^{34} 36$

\section{Adverse events}

We were able to extract dichotomous data for adverse events and calculate RRs for meta-analysis (figure 3). Of the eight studies that reported presence or absence of adverse events, ${ }^{33} 3437-39424345$ three studies reported there were no adverse events, ${ }^{38} 4245$ two reported adverse events 


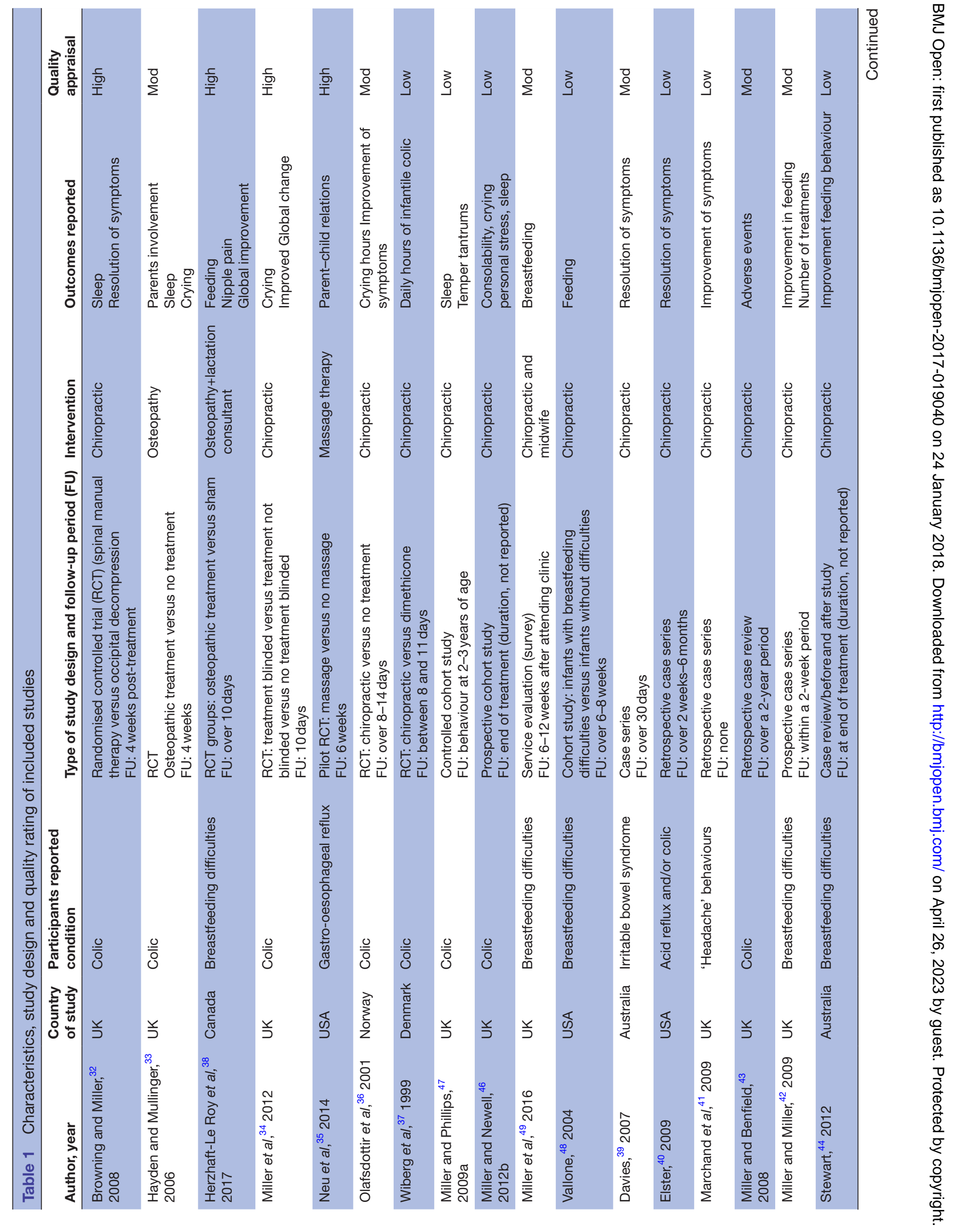


after manual therapy ${ }^{39} 43$ and three reported adverse events (worsening symptoms) in the control group. ${ }^{33} 3437$

Using data from all the studies reporting adverse events, there were 1308 infants exposed to manual therapy and nine non-serious adverse events recorded, giving an incidence rate of seven non-serious events per 1000 infants. Conversely, there were 11 non-serious adverse events in the infants not exposed to manual therapy $(n=97)$, giving an incidence rate of around 110 per 1000 infants.

Figure 3 shows the meta-analysis for the RCTs, which was possible for four studies. ${ }^{33} 343738$ There was an overall RR of 0.12 (95\% CI 0.12 to 0.66 ); that is, those who had manual therapy had an $88 \%$ reduced risk of having an adverse event compared with those who did not have manual therapy.

\section{DISCUSSION}

In this systematic review, we searched for both RCT and non-RCT evidence. We found seven RCTs and 12 non-RCTs investigating the effects of manual therapy on healthy but unsettled, distressed and excessively crying infants treated in primary care.

Using Brontfort et al's approach to overall evidence rating we found: moderate strength evidence for a small positive effective of manual therapy on reduction in crying time, inconclusive evidence for sleep and parentchild relations and no effects for global improvement (table 3).

Previous systematic reviews from 2012 and $2014^{2352}$ concluded there was favourable but inconclusive and weak evidence for manual therapy for infantile colic. Since 2014, two new RCTs have been published: one pilot study RCT $(\mathrm{n}=18)^{35}$ and one high-quality RCT $(\mathrm{n}=97)^{38}$ but neither presented new data on crying time for the meta-analysis. These two new RCTs blinded the parents to treatment, but they reported outcomes on feeding and global improvement and parent-child relations, respectively. This meant we were unable to update the meta-analyses conducted by Dobson $e t \mathrm{al}^{23}$

We considered all methodological study types narratively and looked at: direction of effect, quality of the study and results presented (table 3). However, because the low quality studies were so methodologically flawed, we did not include their results in the final analyses (this indicates a need for more scientific rigour in this field of research). We were still able to review the effects of manual therapy on multiple outcomes in 12 of our 19 selected studies. With the exception of reduced crying time, the findings were inconclusive, and the absence of effect shown for global improvements might suggest that the reduction in crying time of just over 1 hour was not sufficient enough to be meaningful for parents.

We anticipated that there would be more measurement of outcomes related to parent satisfaction and confidence or parent-child relations, but only five studies reported these outcomes. ${ }^{33} 35464950$ This paucity of information about the reciprocity of parent-infant 


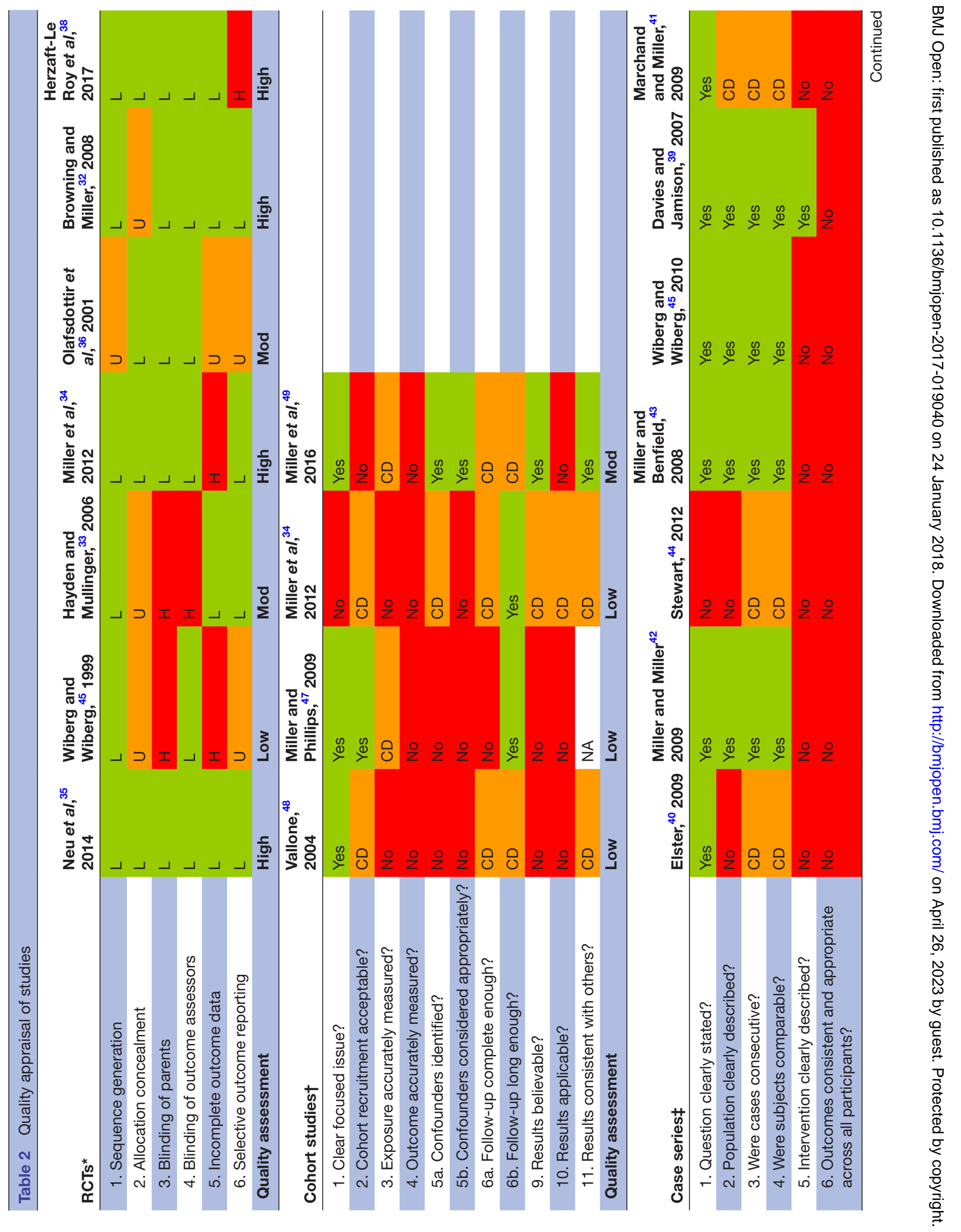




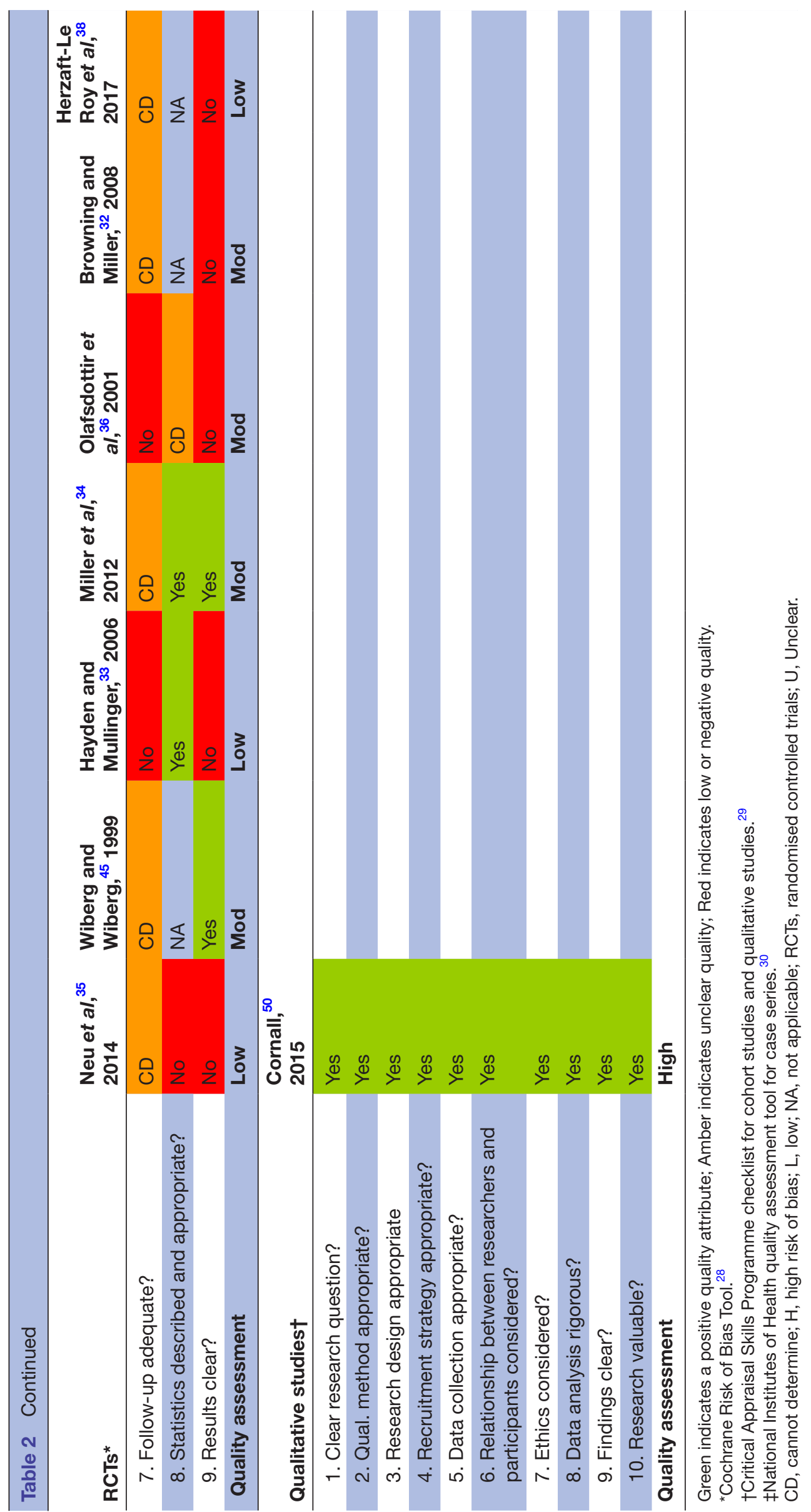




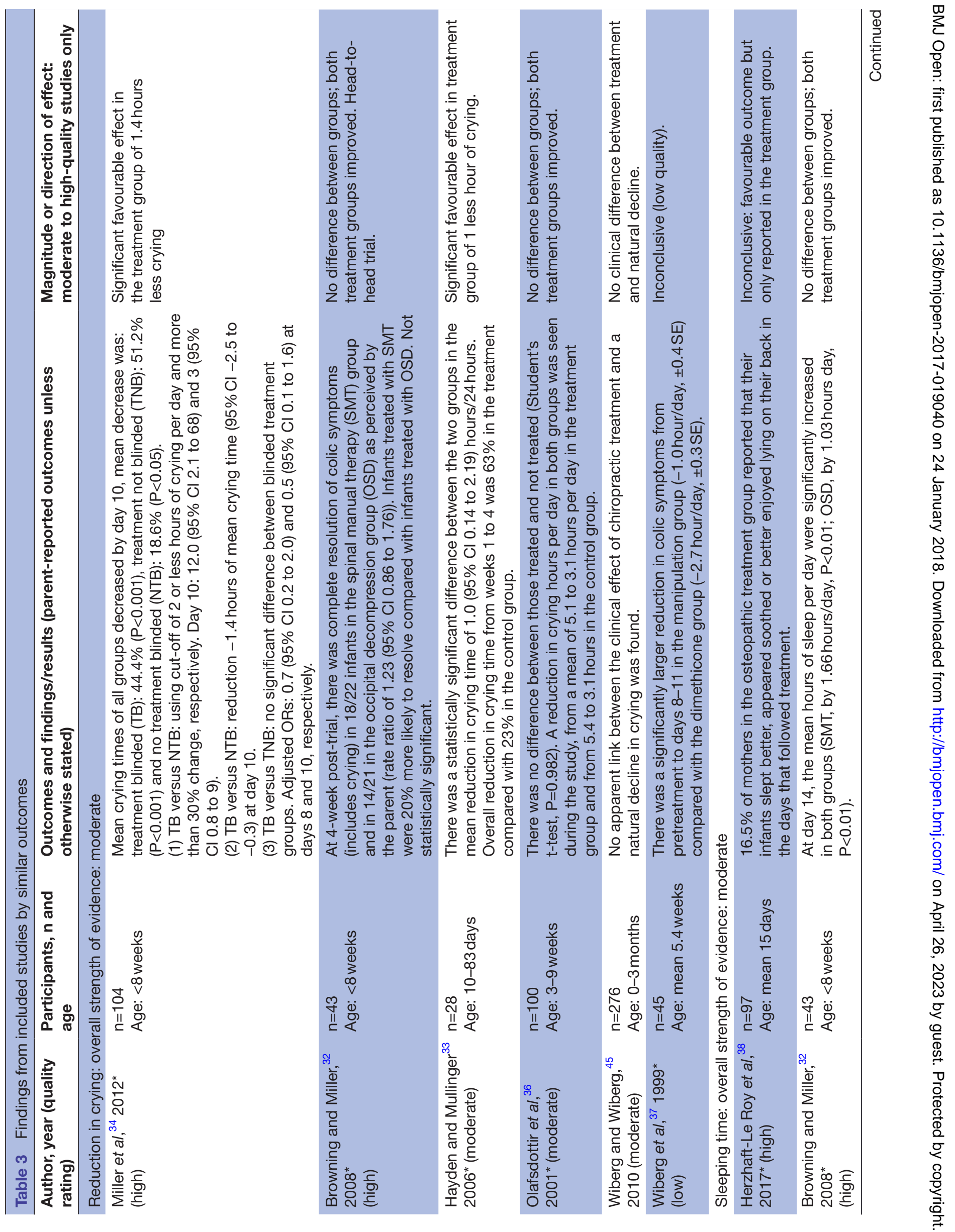




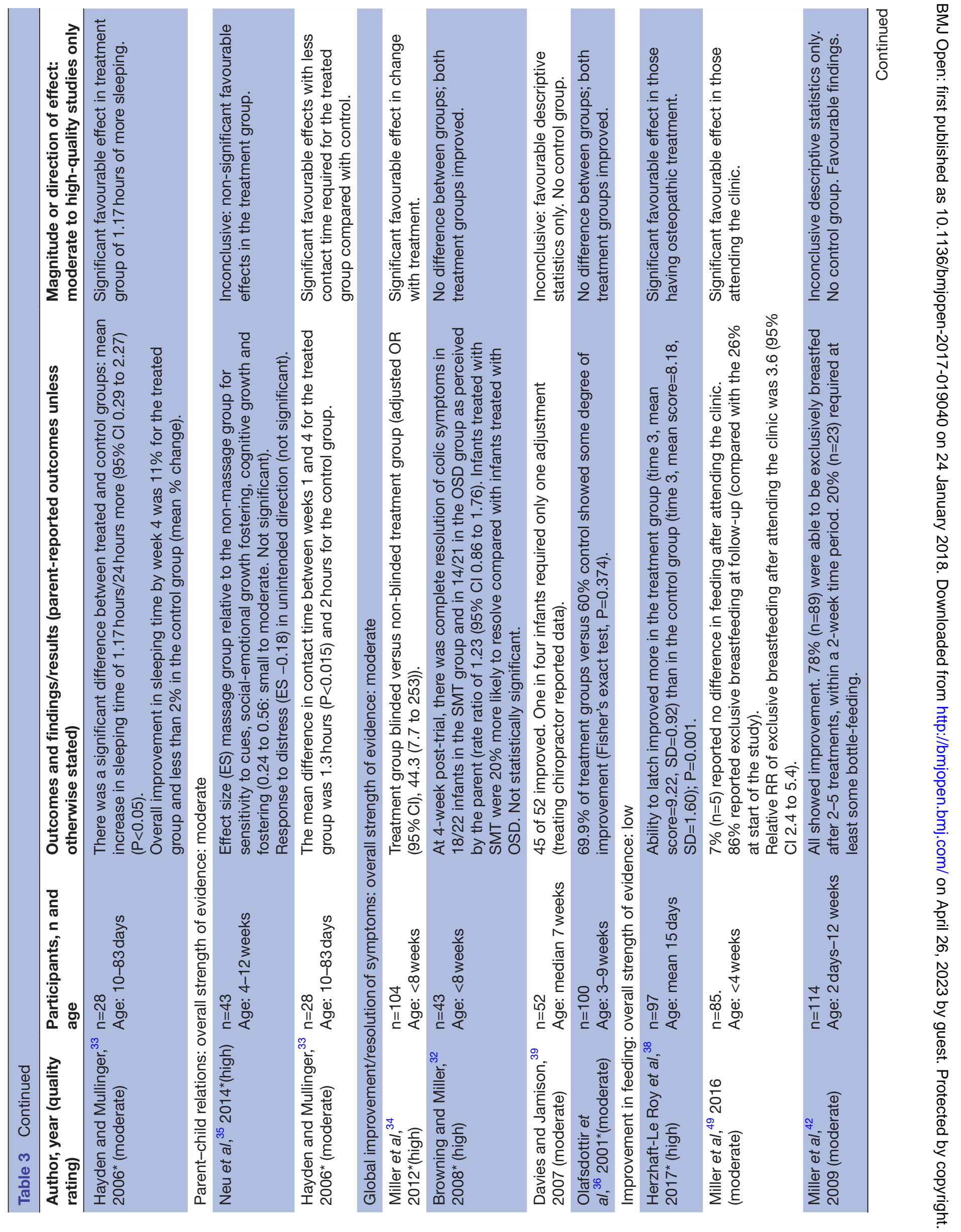




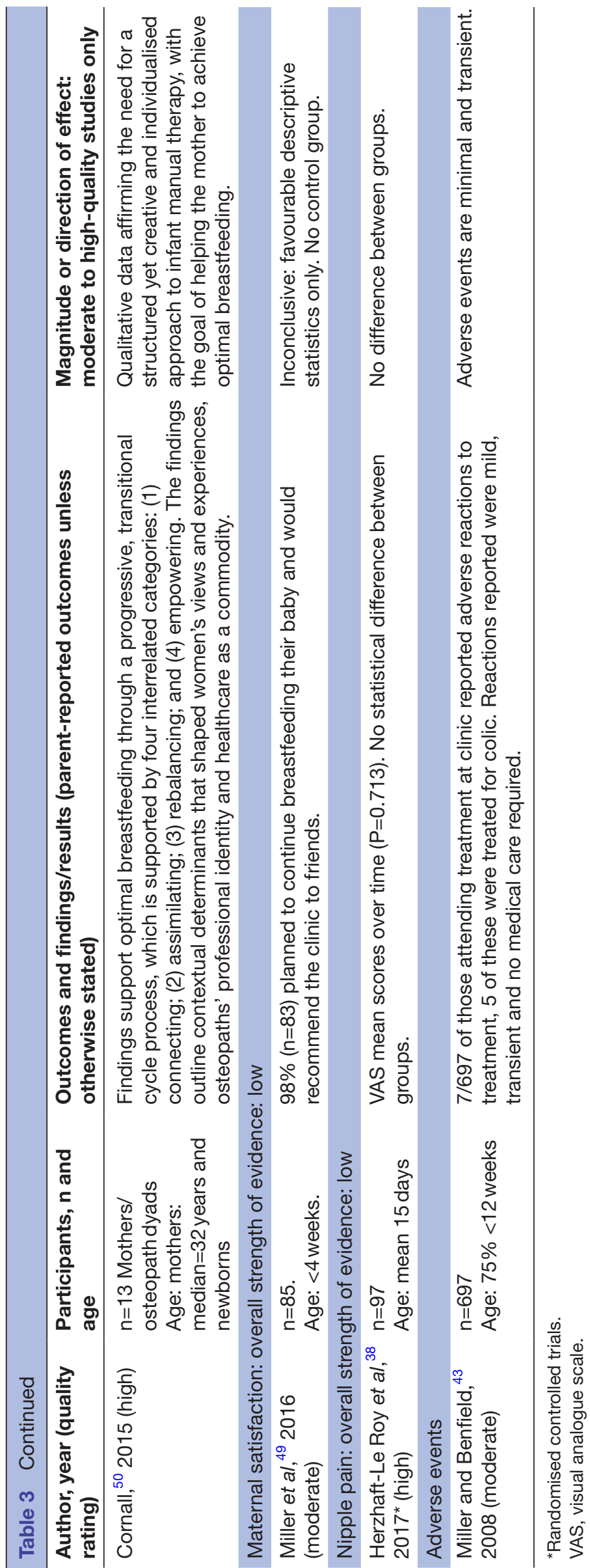




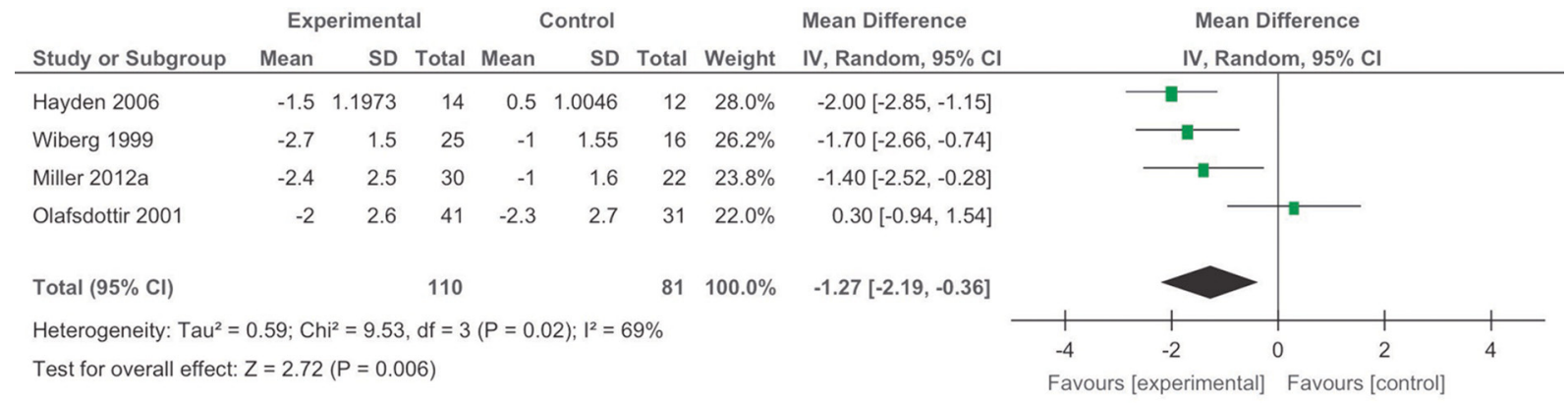

Figure 2 Reduction in crying: RCTs mean difference. *Like Dobson et al, ${ }^{23}$ we were unable to determine the SD for the Olafsdottir et $a^{36}$ data. The Dobson review assigned the SD of change scores based on the correlation coefficient of other, similar studies, because personal correspondence was not successful with the author. We used the data from the Dobson et al review. ${ }^{*}$ Miller $^{34}$ is the same study labelled Miller ${ }^{46}$ in the Dobson review, which was a conference report in advance of the 2012 publication.

psychosocial development indicates a gap in the literature considering the importance of the parentinfant dyad in positive bonding ${ }^{53}$ and the relationship between parent mood and psychosocial development of infants. ${ }^{54-57}$

\section{Results in context with other research}

The Cochrane review by Dobson et $a l^{23}$ included two studies that we excluded because they were not peer reviewed: one a master's thesis ${ }^{58}$ and one from conference proceedings. ${ }^{59}$ We repeated the Dobson et al sensitivity meta-analysis for peer-reviewed studies only, using their imputed SD for one study. ${ }^{36}$ The data extracted were the same, but the meta-analysis results were slightly different due the different versions of RevMan assigning different weights (we used RevMan V.5.3, while Dobson et al used RevMaN V.5.1). Both showed a significant reduction in the weighted mean difference of just over 1 hour in daily crying time $\left(-1.01\right.$ hours $(95 \% \text { CI }-1.78 \text { to }-0.24)^{23}$ vs -1.27 hours (95\% CI -2.19 to -0.36$)$ ). As mentioned above, whether this reduction of around 1 hour of daily crying is meaningful to parents remains to be answered.

The $\mathrm{I}^{2}$ statistic in our meta-analysis and Dobson et $a l \mathrm{~s}^{23}$ were $69 \%$ and $55 \%$, respectively, indicating heterogeneity between the studies analysed. This was not unexpected due to the potential variation in treatments (and hence effects), loose diagnostic criteria and the power of the samples for the RCTs. Therefore, the results have to be considered with caution and are likely to change with further research. The meta-analysis helps illustrate and indicate that future research in this field requires well-powered studies, flexible but protocolised treatment and parental blinding.

Dobson et $a t^{23}$ conducted a sensitivity meta-analysis to explore parent blinding to their infant's treatment (Miller $e t a l^{34}$ and Olafsdottir $e t a l^{36}$ ), and interestingly, their results showed that there was no difference in crying time between groups with blinding.

Our searches also revealed 19 references to other systematic reviews of manual therapy paediatric care for conditions that were not the focus of our review, for example, otitis media, asthma, cerebral palsy and motor development. Our review draws similar conclusions to these other reviews; that is, more high-quality RCTs are needed, but methodological problems with research in this field might preclude researchers taking on this challenge. The gold standard to test effectiveness is the RCT, but doubleblinding is not possible (one cannot blind the treating therapist) and some parents are reluctant to blinding and being separated from their child. Other issues particular to allied, complementary and alternative therapies include: loose definitions and diagnostic criteria, describing and/ or protocolising interventions that are bespoke and determining the active elements of these multicomponent interventions. These problems are further compounded by the self-limiting nature of many childhood conditions.

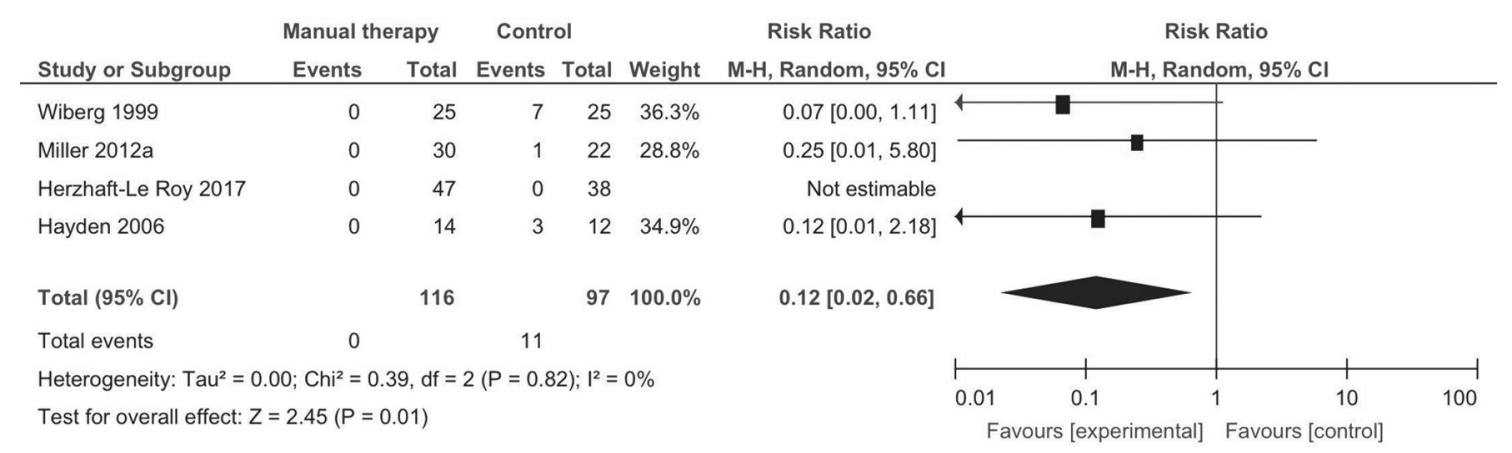

Figure 3 Adverse events meta-analysis: RCTs relative risk. RCTs, randomised conrolled trials. 
These methodological issues may help explain the equivocal findings, small numbers recruited and low-quality assessments presented in systematic reviews.

Data about non-specific effects of treatment, such as the impact of care on parental confidence, and clinician reassurance were not found, possibly because these are difficult to assess as direct, indirect or independent of the study intervention. In one study we reviewed, ${ }^{36}$ all infants and parents received the same support, advice and non-manual therapy care. They found no difference in outcomes between the group who had manual therapy in addition, and both groups improved over time. The authors of this study suggested that the counselling, support and natural progression of the condition played a more powerful role than the manual therapy.

It remains unclear what the active components of a manual therapy consultation are, but we suggest that it would be valuable to understand why parents seek manual therapy care, despite the presence of other healthcare providers.

\section{Safety}

The safety data we extracted regarding adverse events indicated that manual therapy is a relatively low risk intervention, reflecting similar findings in other studies. ${ }^{24}$ The definitions of adverse events recorded in the studies reviewed ranged from 'worsening symptoms' to seeking other forms of care: a comprehensive prospective cohort study specifically focused on adverse events in children is necessary to draw better conclusions.

\section{Strengths and limitations}

This was a comprehensive and rigorously conducted review that included studies in all languages, including a growing number of articles published from China (titles and abstracts were in English for indexing). There was one Chinese paper that was selected for full paper review. We translated this article, but we were unable to fully interpret and understand the treatment given and the outcomes that related to Chinese Traditional Medicine energy points. ${ }^{51}$ In other words, the therapeutic paradigm presented was beyond our knowledge from a Western medicine perspective.

Inclusion criteria were specific to our population of interest, that is, thriving infants who were inexplicably unsettled, distressed and excessively crying who were treated in primary care. This symptom-based approach to selection permitted the inclusion of studies relating to various diagnoses, for example, breastfeeding, gastric and behavioural problems. However, this latitude could also be interpreted as a weakness, since definitions of unsettledness, distress and excessive crying and otherwise healthy were not always clear. Perhaps a more stringent, universally accepted definition of 'colic' is required. We may have failed to include some studies due to the authors' descriptions of their populations.

\section{Future research}

Outcomes for parental satisfaction and confidence were under-researched, and we did not find much data about these. Collecting parent outcomes may provide more informative data about the active components of care.

A well-powered RCT with parental blinding, blinded assessment of reported outcomes, testing both non-specific and manual therapy effects of manual therapist care is needed to supplement research in this area.

\section{CONCLUSIONS}

We found moderate favourable evidence for the reduction in crying time in infants receiving manual therapy care (around 1 hour per day), but this may change with further research evidence. We still do not know if this result is meaningful to parents or if the reduction is due to the manual therapy component of care or other aspects of care. For other outcomes, the strength of evidence was low and inconclusive.

Contributors DC conceptualised and designed the study, contributed to the data selection, extraction and analysis, drafted the initial manuscript, reviewed and revised the manuscript and approved the final manuscript submitted. CM managed the data, contributed to the data selection and extraction and did the metaanalyses, reviewed and revised drafts of the manuscript and approved the final manuscript submitted. AP and JE contributed to the data selection and extraction, reviewed and revised drafts of the manuscript and approved the final manuscript submitted. All authors approved the final manuscript as submitted and agree to be accountable for all aspects of the work.

Funding This research received no specific grant from any funding agency in the public, commercial or not-for-profit sectors.

Competing interests $\mathrm{CM}$ had financial support from the National Council for Osteopathic Research from crowd-funded donations.

Patient consent Not required.

Provenance and peer review Not commissioned; externally peer reviewed.

Data sharing statement Full datasets, analyses and all full searches are available on request from the corresponding author at d.carnes@qmul.ac.uk. No individual patient level data was used in this study.

Open Access This is an Open Access article distributed in accordance with the Creative Commons Attribution Non Commercial (CC BY-NC 4.0) license, which permits others to distribute, remix, adapt, build upon this work non-commercially, and license their derivative works on different terms, provided the original work is properly cited and the use is non-commercial. See: http://creativecommons.org/ licenses/by-nc/4.0/

(c) Article author(s) (or their employer(s) unless otherwise stated in the text of the article) 2018. All rights reserved. No commercial use is permitted unless otherwise expressly granted.

\section{REFERENCES}

1. Don N, McMahon C, Rossiter C. Effectiveness of an individualized multidisciplinary programme for managing unsettled infants. $J$ Paediatr Child Health 2002;38:563-7.

2. Hiscock $\mathrm{H}$, Jordan B. 1. Problem crying in infancy. Med J Aust 2004;181:507-12.

3. Johnson JD, Cocker K, Chang E. Infantile Colic: Recognition and Treatment. Am Fam Physician 2015;92:577-82.

4. McCallum SM, Rowe HJ, Gurrin L, et al. Unsettled infant behaviour and health service use: a cross-sectional community survey in Melbourne, Australia. J Paediatr Child Health 2011;47:818-23.

5. Morris S, James-Roberts IS, Sleep J, et al. Economic evaluation of strategies for managing crying and sleeping problems. Arch Dis Child 2001;84:15-19. 
6. Vik T, Grote V, Escribano J, et al. Infantile colic, prolonged crying and maternal postnatal depression. Acta Paediatr 2009;98:1344-8.

7. Overpeck MD, Brenner RA, Trumble AC, et al. Risk factors for infant homicide in the United States. N Engl J Med 1998;339:1211-6.

8. Hall B, Chesters J, Robinson A. Infantile colic: a systematic review of medical and conventional therapies. $J$ Paediatr Child Health 2012;48:128-37.

9. Miller J, Weber S. Is infant colic an allergic reaction to cow's milk: What is the evidence? J. Clin Chiro.Pediatr 2013:14:1097-102.

10. Sung V, CollettS deGT, et al. Probiotics to prevent or treat excessive infant crying: systematic review and meta-analysis. JAMA 2013;167:1150-7.

11. Sung V, Hiscock $H$, Tang ML, et al. Treating infant colic with the probiotic Lactobacillus reuteri: double blind, placebo controlled randomised trial. BMJ 2014;348:g2107.

12. Ernst E. Chiropractic spinal manipulation for infant colic: a systematic review of randomised clinical trials. Int J Clin Pract 2009;63:1351-3.

13. Langkau J, Miller J. An investigation of musculoskeletal dysfunction in infants includes a case series of KISS diagnosed children. J. Clin Chiro.Pediatr 2012;13:958-67.

14. Rao MR, Brenner RA, Schisterman EF, et al. Long term cognitive development in children with prolonged crying. Arch Dis Child 2004;89:989-92.

15. St James-Roberts I, Peachey E. Distinguishing infant prolonged crying from sleep-waking problems. Arch Dis Child 2011;96:340-4.

16. Wolke D, Bilgin A, Samara M. Systematic review and meta-analyses: fussing and crying durations and prevalence of colic in infants. $J$ Pediatr 2017;185:55-61.

17. Barr RG. Changing our understanding of infat Colic. Arch Pediatr Adolesc Med 2002;156:1172-4.

18. Douglas PS, Hiscock H. The unsettled baby: crying out for an integrated multidisciplinary primary care approach.

19. Talachian E, Bidari A, Rezaie MH. Incidence and risk factors for infantile colic in Iranian infants. World J Gastroenterol 2008;14:4662-6.

20. Kurth E, Spichiger E, Cignacco E, et al. Predictors of crying problems in the early postpartum period. J Obstet Gynecol Neonatal Nurs 2010;39:250-62.

21. Dihigo SK. New strategies for the treatment of colic: modifying the parent/infant interaction. J Pediatr Health Care 1998;12:256-62.

22. Wolke D, Gray P, Meyer R. Excessive infant crying: a controlled study of mothers helping mothers. Pediatrics 1994;94:322-32.

23. Dobson D, Lucassen PL, Miller JJ, et al. Manipulative therapies for infantile colic. Cochrane Database Syst Rev 2012;12:CD004796.

24. Todd AJ, Carroll MT, Robinson A, et al. Adverse Events Due to Chiropractic and Other Manual Therapies for Infants and Children: A Review of the Literature. J Manipulative Physiol Ther 2015;38:699-712.

25. Wessel MA, Cobb JC, Jackson EB, et al. Paroxysmal fussing in infancy, sometimes called colic. Pediatrics 1954;14:421-35.

26. Hyman PE, Milla PJ, Benninga MA, et al. Childhood functional gastrointestinal disorders: neonate/toddler. Gastroenterology 2006;130:1519-26.

27. Software. Melbourne, Australia: Csr: Veritas Health Innovation. http:// www.covidence.org

28. Higgins J, Green S, eds. Cochrane Handbook for Systematic Reviews of Interventions Version 5.1.0 [updated March 2011]: The Cochrane Collaboration, 2011. http://www.handbook.cochrane.org

29. CASP: Critical Appraisal Skills Programme (CASP) 2014. CASP Checklists (URL used). Oxford: CASP, 2014.

30. National Institutes of Health (NIH). Quality Assessment Tool for Case Series Studies. 2014. https://www.nhlbi.nih.gov/health-pro/ guidelines/in-develop/cardiovascular-risk-reduction/tools/case_ series

31. Bronfort G, Haas M, Evans R, et al. Effectiveness of manual therapies: the UK evidence report. Chiropr Osteopat 2010;18:3.

32. Browning M, Miller J. Comparison of the short-term effects of chiropractic spinal manipulation and occipito-sacral decompression in the treatment of infant colic: a single-blinded, randomised, comparison trial. Clinical Chiropractic 2008;11:122-9.

33. Hayden C, Mullinger B. A preliminary assessment of the impact of cranial osteopathy for the relief of infantile colic. Complement Ther Clin Pract 2006;12:83-90.

34. Miller JE, Newell D, Bolton JE. Efficacy of chiropractic manual therapy on infant colic: a pragmatic single-blind, randomized controlled trial. J Manipulative Physiol Ther 2012;35:600-7.
35. Neu M, Schmiege SJ, Pan Z, et al. Interactions during feeding with mothers and their infants with symptoms of gastroesophageal reflux. J Altern Complement Med 2014;20:493-9.

36. Olafsdottir E, Forshei S, Fluge G, et al. Randomised controlled trial of infantile colic treated with chiropractic spinal manipulation. Arch Dis Child 2001;84:138-41.

37. Wiberg JM, Nordsteen J, Nilsson N. The short-term effect of spinal manipulation in the treatment of infantile colic: a randomized controlled clinical trial with a blinded observer. J Manipulative Physiol Ther 1999;22:517-22.

38. Herzhaft-Le Roy J, Xhignesse M, Gaboury I. Efficacy of an Osteopathic Treatment Coupled With Lactation Consultations for Infants' Biomechanical Sucking Difficulties. J Hum Lact 2017;33:165-72.

39. Davies NJ, Jamison JR. Chiropractic management of irritable baby syndrome. Chiropr J Aust 2007;37:25-9.

40. Elster E. Sixteen infants with acid reflux and colic undergoing upper cervical chiropractic care to correct vertebral subluxation: A retrospective analysis of outcome. J Pediatr Matern \& Fam Health Chiropr 2009.

41. Marchand AM, Miller JE, Mitchell C. Diagnosis and chiropractic treatment of infant headache based on behavioral presentation and physical findings: a retrospective series of 13 cases. J Manipulative Physiol Ther 2009;32:682-6.

42. Miller JE, Miller L, Sulesund AK, et al. Contribution of chiropractic therapy to resolving suboptimal breastfeeding: a case series of 114 infants. J Manipulative Physiol Ther 2009;32:670-4.

43. Miller JE, Benfield K. Adverse effects of spinal manipulative therapy in children younger than 3 years: a retrospective study in a chiropractic teaching clinic. J Manipulative Physiol Ther 2008:31:419-23.

44. Stewart A. Paediatric chiropractic and infant breastfeeding difficulties: A pilot case series study involving 19 cases. Chiropr $J$ Aust 2012;42:98-107.

45. Wiberg KR, Wiberg JM. A retrospective study of chiropractic treatment of 276 danish infants with infantile colic. J Manipulative Physiol Ther 2010;33:536-41.

46. Miller J, Newell D. Prognostic significance of subgroup classification for infant patients with crying disorders: A prospective cohort study. J Can Chiropr Assoc 2012;56:40-8.

47. Miller JE, Phillips HL. Long-term effects of infant colic: a survey comparison of chiropractic treatment and nontreatment groups. $J$ Manipulative Physiol Ther 2009;32:635-8.

48. Vallone S. Chiropractic Evaluation and Treatment of Muskuloskeletal Dysfunction in Infants Demonstrating. J Clin Chiro Pediatrics 2004;6:349-68

49. Miller J, Beharie MC, Taylor AM, et al. Parent Reports of Exclusive Breastfeeding After Attending a Combined Midwifery and Chiropractic Feeding Clinic in the United Kingdom: A CrossSectional Service Evaluation. J Evid Based Complementary Altern Med 2016;21:85-91.

50. Cornall D. Promoting optimal breastfeeding through the osteopathic therapeutic cycle. Australia: Victoria University, 2015.

51. Wq H. Clinical observation on manipulation without syndrome differentiation in treating infantile diarrhea]. Zhong Xi Yi Jie He Xue Bao/Chin J Integr Med 2004;2:220-1.

52. Clar C, Tsertsvadze A, Court R, et al. Clinical effectiveness of manual therapy for the management of musculoskeletal and nonmusculoskeletal conditions: systematic review and update of UK evidence report. Chiropr Man Therap 2014;22:12.

53. Costa R, Figueiredo B. Infant's psychophysiological profile and temperament at 3 and 12 months. Infant Behav Dev 2011;34:270-9.

54. Barr RG. Colic and crying syndromes in infants. Pediatrics 1998;102:1282-6.

55. Canivet CA, Ostergren PO, Rosén AS, et al. Infantile colic and the role of trait anxiety during pregnancy in relation to psychosocial and socioeconomic factors. Scand J Public Health 2005;33:26-34.

56. Rautava P, Helenius H, Lehtonen L. Psychosocial predisposing factors for infantile colic. BMJ 1993;307:600-4.

57. Reijneveld SA, Brugman E, Hirasing RA. Excessive infant crying: the impact of varying definitions. Pediatrics 2001;108:893-7.

58. Heber A, Senger U, [DIE OSTEOPATHISCHE BEHANDLUNGBEI3MONATSKOLIK IM VERGLEICHZURKONVENTIONELLEN THERAPIE]. Osteopathic Treatment Of Infantile Colic Masters thesis. Germany: Akademie für Osteopathie (AFO), 2003.

59. Mercer C. A study to determine the efficacy of chiropractic spinal adjustments as a treatment protocol in the management of infantile colic. Durban, SA: Technikon Natal, Durban University, 1999. 